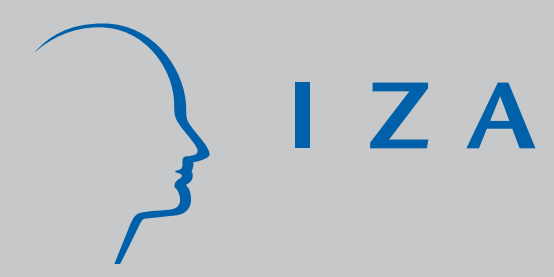

IZADP No. 3301

Mexican Immigrants, the Labor Market and the Current Population Survey: Seasonality Effects, Framing Effects, and Sensitivity of Results

Fernando A. Lozano

Todd Sorensen

J anuary 2008 


\title{
Mexican Immigrants, the Labor Market and the Current Population Survey: Seasonality Effects, Framing Effects, and Sensitivity of Results
}

\author{
Fernando A. Lozano \\ Pomona College \\ Todd Sorensen \\ University of California, Riverside \\ and IZA
}

Discussion Paper No. 3301

January 2008

IZA

P.O. Box 7240

53072 Bonn

Germany

Phone: +49-228-3894-0

Fax: +49-228-3894-180

E-mail: iza@iza.org

Any opinions expressed here are those of the author(s) and not those of IZA. Research published in this series may include views on policy, but the institute itself takes no institutional policy positions.

The Institute for the Study of Labor (IZA) in Bonn is a local and virtual international research center and a place of communication between science, politics and business. IZA is an independent nonprofit organization supported by Deutsche Post World Net. The center is associated with the University of Bonn and offers a stimulating research environment through its international network, workshops and conferences, data service, project support, research visits and doctoral program. IZA engages in (i) original and internationally competitive research in all fields of labor economics, (ii) development of policy concepts, and (iii) dissemination of research results and concepts to the interested public.

IZA Discussion Papers often represent preliminary work and are circulated to encourage discussion. Citation of such a paper should account for its provisional character. A revised version may be available directly from the author. 


\section{ABSTRACT \\ Mexican Immigrants, the Labor Market and the Current Population Survey: Seasonality Effects, Framing Effects, and Sensitivity of Results}

In this paper we compare estimates of immigrants' labor supply assimilation profiles using the Current Population Survey Annual Demographic Files (March ADS) and the Current Population Survey Outgoing Rotation Groups (ORGs). We use a measure that is seemingly consistent across both surveys: usual weekly hours of work in the main job. Our results indicate that the two surveys produce dramatically different estimates of the change in average hours of work as immigrants' years in the United States increase: estimates from the March ADS predict much steeper hour's assimilation profiles than do estimates obtained from the ORGs. We argue that these differences stem from two separate factors that differentiate the data. First, the ADS and ORG frame the usual hours worked question differently. Also, differences in the timing of the surveys may produce seasonality effects that differentially affect the composition of recent and earlier migrants, thereby changing assimilation profiles.

JEL Classification: J16, J22

Keywords: $\quad$ immigration, March CPS, CPS outgoing rotations, hours of work

Corresponding author:

Todd Sorensen

Department of Economics

University of California, Riverside

4128 Sproul Hall

Riverside, CA 92521-0427

USA

E-mail: todd.sorensen@ucr.edu 


\section{Introduction}

The stock of Mexican migrants living in the United States is both large and growing. By 2000, these 9.2 million Mexican immigrants comprised 29.3\% of the entire foreign born population in the United States, over one-third of the foreign born male workforce, and $5 \%$ of the total population of the United States (Borjas and Katz, 2007). Of particular interest to academics and policymakers are recent migrants. As of early 2007, there were an estimated 7 million Mexican immigrants who had entered the U.S. since 1990 (Pew Hispanic Center, 2007).

Attitudes towards these recent immigrants, as well as the labor market outcomes for these immigrants, will ultimately depend upon their patterns of assimilation. These recent migrants are also increasingly likely to settle in areas that, until recently, have had little to no foreign born population (Card and Lewis, 2005). Unsurprisingly, there is considerable concern regarding issues of assimilation in these previously homogenous areas.

In order to efficiently conduct policy, it is necessary to properly estimate Mexican immigrants' labor market performance and associated patterns of assimilation. In this paper, we examine how differences across data sets may affect estimates. Using data from the Outgoing Rotations Groups (ORG) and the March Annual Demographic Files (ADS) of the Current Population Survey (CPS), we examine one outcome variable that is seemingly consistent across both products: the usual hours worked in the main job by Mexican migrants to the U.S. We particularly pay attention to how the length of the work week changes as workers' tenure in the U.S. increases. We find that there are significant and important differences in these measures, depending upon which CPS product is used: 
the ADS which is collected mainly in March, or the ORG which is collected throughout the year. As hourly wages are computed in both surveys using the usual hours worked in the main job variable that we consider, these findings have important implications for researchers studying wage assimilation profiles as well.

The ADS and ORG have been used extensively by social scientists to evaluate the labor market outcomes of immigrants. For example the ADS is used in Blau and Kahn (2005), Card (2005), Duncan and Trejo (2005), among many others. The ORG has been widely used as well, for example by Card (1990) or Lozano (2007). While differences in these surveys in measuring immigrant outcomes have yet to be documented, researchers have extensively documented that there exist differences in estimates produced by the two datasets when analyzing the distribution of earnings of the U.S. population (Lemieux 2006 and Autor et al 2007). Therefore, it seems equally important to analyze whether, and how, estimates of immigrant's outcomes differ across surveys, in particular for immigrants from Mexico. We can do this since the question asking usual hours of work in the main job is seemingly consistent across surveys ${ }^{1}$, the only difference is that usual hours in the ADS refers to the main job last year, while in the CPS ORG to the main job at the time of the survey. Still, averages from year $t+1$ in the ADS must equal averages from year $t$ in the CPS ORG.

Our results suggest that there is a strong cyclical component to the length of the work week for Mexican immigrants. Additionally, this cycle is much more pronounced for recent immigrants from Mexico than for earlier Mexican migrants. This leads to

\footnotetext{
${ }^{1}$ The ADS question is asked to all respondents who held a job in the previous year (WORKYN=1) and is "In the weeks that ... worked how may hours did ... usually work per week?" while in the ORG the question is asked to everybody with a job (lfsr=1 or lfsr=2) and the question is "How many hours per week does...USUALLY work at this job?"
} 
estimates of hours assimilation profiles taken from the ADS data, which is collected mostly in March, that differ from those taken from the ORG, which includes data from throughout the year (conditional upon cohort of arrival). As hourly wages are computed using usual hours in these datasets, this result implies that estimates of wage assimilation profiles obtained from the two datasets differ as well.

We believe that differences between the ADS and ORG surveys result from two separate sources: differences in the framing of the questions asked by the two surveys (i.e. reported "hours usually worked" in the main job for the ORG versus reported "hours in the typical week during the preceding year" for the ADS), and seasonality related differences. $^{2}$ The presence of these two sources is evidenced by the fact that estimates from the two surveys still differ even when using only the ORG surveys collected during February, March and April (better replicating the ADS sample, and reflecting economic conditions in the months in which the March ADS is collected).

The rest of this paper is structured as follows. Section 2 describes the data, questions asked therein and the main differences between the surveys, Section 3 estimates immigrants’ assimilation effects using Borjas’ (1985, 1995) synthetic cohorts approach, Section 4 discusses possible explanations for the different results in the two surveys, and Section 5 concludes.

\footnotetext{
${ }^{2}$ While the ADS question refers specifically to the previous year, it is not hard to believe that recall error issues may lead the survey respondents to give answers that may be more reflective of hours recently worked than of the true average length of the work week in the prior year.
} 


\section{Data}

The CPS survey is collected from a representative sample of households in the United States on a monthly basis ${ }^{3}$. Each monthly sample is divided into eight different rotations, and each rotation is representative of the United States. Each rotation group is surveyed for four consecutive months, taken out of the sample for eight months, and then returned to the sample for four final months. In the fourth and eight months a special labor market supplement is asked of all adults above 16 years of age. This survey is known as the Outgoing Rotation Survey. ${ }^{4}$ The rotations are illustrated in an example for 2007 shown in Table 1. The columns represent the month of the survey, and the rows represent the different rotations surveyed in those months. For example, we see that the May 2007 survey includes rotations that first started in February, March, April and May of both 2006 and 2007. As the February 2007 rotation was in its $4^{\text {th }}$ survey month and the February 2006 rotation was in its $8^{\text {th }}$ and final survey month, these were the rotations to which the ORG labor market supplement was administered.

The Annual Demographic Survey is a special supplement to the CPS. It contains a battery of questions regarding the respondent's income in the prior year. The purpose of collecting the supplement data in March is motivated by the belief that annual income information will be most accurate during March, as that is when most households prepare their income taxes; though it is not intuitively obvious that any similar argument could be made about the number of hours worked. The ADS for year $t$ includes all rotations that are in the March sample in year $t$. It also includes all Hispanic households in the previous November sample and in the $1^{\text {st }}$ and $5^{\text {th }}$ rotation in following April sample. In addition the

\footnotetext{
${ }^{3}$ The survey is collected on the week containing the $19^{\text {th }}$ of each month and the reference week contains the $12^{\text {th }}$ of each month.

${ }^{4}$ In this paper we use the CPS ORG collection prepared by the National Bureau of Economic Research.
} 
ADS includes all non-Hispanic non-White households who are in the following rotations: the $1^{\text {st }}, 5^{\text {th }}, 6^{\text {th }}, 7^{\text {th }}$ and $8^{\text {th }}$ rotation of the previous November sample and the $1^{\text {st }}$ and $5^{\text {th }}$ rotation of the following April sample. The ADS also includes non-Hispanic White households with children 18 years of age or younger who are in the $1^{\text {st }}, 5^{\text {th }}, 6^{\text {th }}, 7^{\text {th }}$ and $8^{\text {th }}$ rotation of the previous November sample and the $1^{\text {st }}$ and $5^{\text {th }}$ rotation of the following April sample. Importantly, the samples added are completely independent to the March sample, and in total the March ADS includes 18 rotations of Hispanic households, 15 rotations each of non-Hispanic non-White and non-Hispanic White with children 18 or under, and 8 rotations of all other households. The ADS is administered to the households from the March and April sample in the respective months. To the Hispanic households from the November sample, the survey is administered in March, and to the non-Hispanic households from the November sample the survey is administered either in February or April. $^{5}$

Our data is taken from years 1994 to 2006, and includes all men age 25-64 in both surveys. We chose to exclude women from this sample in order to focus on the issues related to survey differences without at the same time trying to tackle issues related with the labor supply of women, which is highly sensitive to family arrangements, either due to tied migrants (Mincer, 1978) or to family labor supply (Baker and Benjamin, 1998). To properly analyze the assimilation of Mexican migrants, we exclude from the sample those who came to the United States before their $16^{\text {th }}$ birthday as well as non-Mexican immigrants. When presenting estimates of assimilation, our reference group is U.S. born non-Hispanic males.

\footnotetext{
${ }^{5}$ Current Population Survey (2002) “Technical Paper 63RV. Design and Methodology” accessed on January 16, 2008 from http://www.census.gov/apsd/techdoc/cps/cps-main.html.
} 
Table 2 presents basic summary statistics across different demographic groups of the sample in both surveys -- note that the number of observations in the ORG is more than twice that of the ADS. Also note that the key demographic characteristics proportion immigrant and age -- across samples do not differ. Perhaps one exception, the individuals observed in the ORG are slightly more likely to be high school dropouts than observations from the ADS. Examining hours worked per week for immigrants in the United States, we find no significant difference between the two surveys -- at least when using disaggregated data.

We see a somewhat different picture once we disaggregate the data by immigrants' tenure in the U.S. In Figure 1 we graph the average hours worked in each quarter in year $t(\operatorname{Feb}(t)-\operatorname{Apr}(t)$; $\operatorname{May}(t)-\operatorname{July}(t)$; $\operatorname{Aug}(t)-\operatorname{Oct}(t)$; $\operatorname{Nov}(t)-\operatorname{Jan}(t+1))$. The top panel represents immigrants who have less than 5 years of labor market experience in the U.S. while the bottom are those with 6 or more years of experience. Three things are clearly seen from the figure: (1) there is a seasonal pattern in hours worked, (2) this seasonal pattern is more pronounced for recent migrants than it is for earlier migrants, (3) troughs in the cycle are likely to occur in March. In fact, among the 22 cycles presented in the two graphs, the March observation represented either the trough or the second lowest point in the cycle 18 times.

Table 3 presents this disaggregated data at a monthly frequency and computes the difference in hours worked by recent and earlier immigrants. Here we see not only the seasonal nature of the length of the work week for recent immigrants, but it also becomes clear that the difference in the length of the work week based on tenure in the U.S. is greatest in the Spring months, especially in March. 
The evidence presented in Figure 1 and Table 3 are at the very least casual evidence that the use of the March conducted ADS may not produce consistent estimates of assimilation profiles: with troughs more likely in March, the ADS will underestimate the average hours of work for Mexican immigrants in the United States, compared to estimates from data collected continuously during the year. With deeper troughs for recent migrants, data from March will also overstate the differences between recent and earlier immigrants -- overestimating assimilation rates. In the next section we conduct a more formal analysis to see if this issue with the data indeed effects assimilation profile estimates.

\section{Analysis of Hours Assimilation Profiles}

Turning our attention to assimilation profiles, in Table 4 we present mean hours of work by Mexican immigrants across categories of tenure in the United States. These means are computed from three samples of data: the ORG for all months, the ORG for only February, March and April ("March ORG" henceforth), and the ADS, conducted primarily in March.

In all three cases, natives work longer hours than immigrants, though this gap narrows as immigrants' tenure in the U.S. increase. A raw estimate of the assimilation profile is the change in weekly hours of work between the most recent and the earliest immigrants. This estimate is positive and significant in all three cases. However, it is much higher for the ADS and March ORG than it is for the full sample of the ORG; consistent with the seasonality issues discussed in the previous section. 
It is well known that a changes-in-cross-sectional approach to estimating an assimilation profile is confounded with entry year cohort quality heterogeneity (Borjas 1985, 1995). To control for cohort heterogeneity we use Borjas’ well known synthetic cohort technique. In what follows, we compute a within cohort estimator (cohort fixedeffects) where we estimate the following ordinary least square regression:

$$
\left(h_{i, t}^{C}-\bar{h}_{t}^{C}\right)=\alpha+\sum_{J=1}^{4} \beta_{J}\left(Y_{i, t, J}^{C}-\bar{Y}_{t, J}^{C}\right)+\varepsilon_{i, t}
$$

Where the superscript $C$ represents one of six arrival cohorts: before 1985, 1985-1989, 1990-1994, 1995-1999, and after 2000. The estimate of each $\beta_{J}$ shows how migrants assimilate as they pass from one tenure category to another. In the response variable: $h_{i, t}^{C}$ represents the weekly hours of work for observation $i$ in year $t$ who arrived in cohort $C$ and $\bar{h}_{t}^{C}$ represents the average weekly hours of work of all men in cohort $C$ in year $t$. The variable $Y_{i, t, J}^{C}$ has a value of one if the observation $i$ in year $t$ from cohort $C$ has been in the United States for $J$ years $-J$ is an indicator for either 0-5 years, 6-10 years, 11-19 years and 20+ years. The corresponding cohort average is represented by $\bar{Y}_{t, J}^{C}$.

Figure 2 shows the coefficients of years in the U.S. on hours of work per week, conditional upon arrival cohort -- they are relative to native workers. The magnitude of the coefficients differs across surveys. The ORG sample yields a negative and marginally significant result, suggesting that immigrants may not be assimilating in the dimension of hours. Both the March ORG and ADS samples yield higher results of this coefficient. Consistent with the seasonality effect; the March ORG gives a positive but insignificant result, while the ADS sample produces a positive and significant estimate. As seasonality effects cannot explain differences between these two estimates - the estimates between 
the CSP ORG and its March sub-sample are not statistically significant -- these results also suggest that there may be a framing effect in how the questions are asked in the two surveys.

Table 5 presents the hours of work predicted using the above estimates of each data sample; Figure 3 represents this graphically for the ORG and for the ADS. From Table 5 and Figure 3, we can again see that the ADS gives steeper estimates of assimilation profiles than do the other data sets. In fact, after conditioning upon cohort, only the ADS predicts assimilation; the ORG dataset shows a mild divergence between immigrant hours and natives' hours. There are two further points worth noting: first, the assimilation profiles from the ADS are statistically significantly greater than the assimilation profiles from the ORG; second, the predicted differences are greater among earlier immigrants than among recent one, suggesting that cohort effects do matter. Still, it is not clear to us why the differences in the conditional estimates are greatest among earlier immigrants. One possible answer is based on Redstone and Massey’s (2004) argument that immigrants' answer to the question “When did you first come to live to the United States” varies across different immigrants, particularly those who are most likely to transition many times between the United States and Mexico.

\section{Possible Sources of Differences in Estimates}

The previous section exposes an important caveat to researchers using only ADS data to study migration: the ADS shows evidence of assimilation, the ORG does not. While a thorough explanation for the cause of this difference is beyond the scope of this paper, it is informative to discuss some of the peculiarities that may have lead to our finding. 
After conditioning upon cohort, it seems that this difference stems not from seasonality effects alone (as evidenced by differences in estimates between the full set of ORGs and the ORGs from only the spring), but also from differences in the survey questions asked (as evidenced by the differences in estimates between the March ADS and ORGs at the same time of the year).

As we argued before, part of the difference is likely due to the different time reference of the question between surveys, where the question in the March CPS refers to "usual hours last year" and the question in the ORG refers to "usual hours" this year. Again, this difference seems to be particularly sensitive for recent immigrants who have no hours of work in the previous year - since they arguably were outside the U.S. -- but positive hours of work this year.

Below we discuss a number of peculiarities related to data gathered in March. While there does not seem to be a pure seasonality effect, considering these issues may shed some light upon how the differences in survey questions asked in the ADS and ORGs may interact with seasonality effects to produce different estimates of the assimilation profiles.

Table 6 presents additional demographic data on migrants appearing in the three samples. One fact that comes to immediate attention is that the total years of "U.S. Experience” is higher in March, suggesting that we see less recent immigrants in the sample. Figure 4 as well shows that the percent of the U.S. population that is comprised of recent immigrants from Mexico dips in March.

Clearly, changes in the relative stocks of recent and earlier immigrants are not sufficient to generate the differences in mean hours worked by these two groups. 
However, the presence of a relatively larger stock of earlier migrants in March brings attention to issues related to cyclical migration (Massey, Durand, and Malone, 2002). If cyclical migration patterns change the tenure composition of the stock of migrants in the U.S., it is reasonable to question whether migration patterns may also change the composition of migrants within each tenure category.

From Figure 5, which shows monthly total number of Border Patrol apprehensions on the southern U.S. border (Hanson and Spilembergo, 1999), it is clear that there is a large increase in the number of migrants crossing into the U.S. starting early each year, peaking in March, and continuing for a couple of months thereafter. This is more evidence that seasonal compositional changes in the type of migrant crossing into the U.S. would likely lead to significantly different composition of migrants in March, compared to other months.

Finally, in Table 7, we see that recent migrants (0-5 years in the U.S.) show the biggest seasonal difference in employment rates at -2.7 percentage points difference between the March ADS and the ORGs. In contrast, the differences for those in the U.S. 6-10 years, $11-20$ years and more than 20 years are, respectively -1.2 percentage points, .5 percentage points, and 1.6 percentage points. Future work will pursue a more in depth study of the possible causes for the "March effect" that we have demonstrated.

\section{Summary}

In this paper we have compared estimates of immigrant's labor market assimilation across two seemingly equivalent surveys. We first find much stronger seasonality in hours worked by new immigrants than for earlier immigrants. As expected, this causes 
estimates of assimilation profiles to be dependent upon the season of the data used to estimate the profile. In particular, the use of the Annual Demographic Survey provides evidence that immigrants are assimilating in the length of their work week, while the Current Population Survey Outgoing Rotation Groups do not. Apart from seasonality, there may be other factors which lead to this difference; this is evidenced by the fact that the differences in estimates between the two surveys attenuate when we limit the Outgoing Rotation Groups to only the months of February, March, and April. Future work will focus on examining whether the "March Effect" has significant effects on estimates of earnings assimilation profiles, and a broader exploration of the causes of the peculiarity of the March data. 


\section{Bibliography}

Autor, David H., Lawrence F. Katz and Melissa S. Kearney (2006). "The Polarization of the U.S. Labor Market”, NBER Working Paper 11986.

Baker, Michael and Dwayne Benjamin (1997). "The Role of the Family in Immigrants' Labor-Market Activity: An Evaluation of Alternative Explanations", The American Economic Review, 87(4), Sep 1997: 705-727.

Baker, Michael and Dwayne Benjamin (1997). "The Role of the Family in Immigrants' Labor-Market Activity: An Evaluation of Alternative Explanations", The American Economic Review, 87(4), Sep 1997: 705-727.

Blau Francine D., Lawrence M. Kahn (2005). “Gender and Assimilation Among Mexican Americans” NBER Working Paper 11512.

Borjas, George J (1985). “Assimilation, Changes in Cohort Quality, and the Earnings of Immigrants.” Journal of Labor Economics, 3(4), October 1985: pp. 463-489.

Borjas, George J (1995). “Assimilation and Changes in Cohort Quality Revisited: What Happened to Immigrant Earnings in the 1980s?” Journal of Labor Economics, 13(2), April 1995: 201-245.

Borjas, George J. and Lawrence F Katz (2007). "The Evolution of the Mexican-Born Workforce in the United States.” In Mexican Immigration to the United States, George J. Borjas eds. The University of Chicago Press, Chicago: 2007.

Card, David (1990). “The Impact of the Mariel Boatlift on the Miami Labor Market” Industrial and Labor Relations Review, Vol. 43, No. 2. (Jan., 1990), pp. 245-257.

Card, David (2005). “Is New Immigration Really So Bad? NBER Working Paper 11547.

Card, David and Ethan G Lewis (2007). "The Diffusion of Mexican Immigrants during the 1990s: Explanations and Impacts.” In Mexican Immigration to the United States, George J. Borjas eds. The University of Chicago Press, Chicago: 2007.

Duncan, Brian and Stephen Trejo (2005). "Ethnic Identification, Intermarriage, and Unmeasured Progress by Mexican Americans”, NBER Working Paper 11423.

Hanson, Gordon (2007). Border Patrol Dataset available at: http://irpshome.ucsd.edu/faculty/gohanson/data.htm

Hanson, Gordon and Antonio Spilembergo (1999). "Illegal Immigration, Border Enforcement, and Relative Wages: Evidence from Apprehensions at the U.S.Mexico Border”, American Economic Review 89(5), Dec 1999: 1337-1357. 
Lemieux, Thomas (2006). "Increasing Residual Wage Inequality: Composition Effects, Noisy Data, or Rising Demand for Skill?”, American Economic Review 96(3), June 2006: 461-98.

Lozano, Fernando (2007). "Coming to Work? The Hours of Work of Mexican and Central American Immigrants in America.” Working Paper.

Massey, Douglas S.; Jorge Durand, and Nolan J. Malone (2002). Beyond Smoke and Mirrors: Mexican Immigration in an Era of economic Integration, Russell Sage Foundation, New York: 2002.

Mincer, Jacob (1978). “Family Migration Decisions”, Journal of Political Economy, 86, 1978: 749-773.

Pew Hispanic Center (2007). "Indicators of Recent Migration Flows from Mexico.” 


\section{Figure 1:}

Average Weekly Hours of Work of Mexican Immigrants

a. Recent Immigrants: 0-5 Years in US

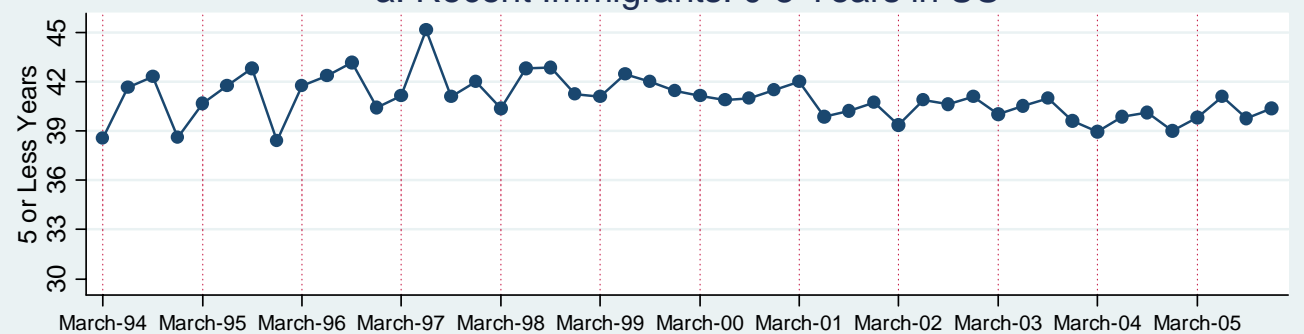

March-94 March-95 March-96 March-97 March-98 March-99 March-00 March-01 March-02 March-03 March-04 March-05

b. Earlier Immigrants: $6+$ Years in US

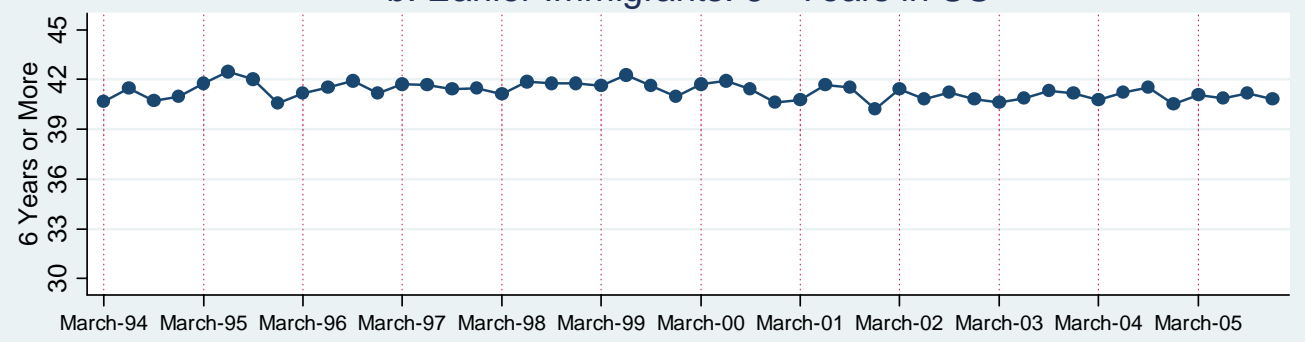

Source: All Employed males born in Mexico in CPS ORG 1994-2006

\section{Figure 2:}

Within Cohort Coefficient Estimators Change Hours/ Change Years U.S.
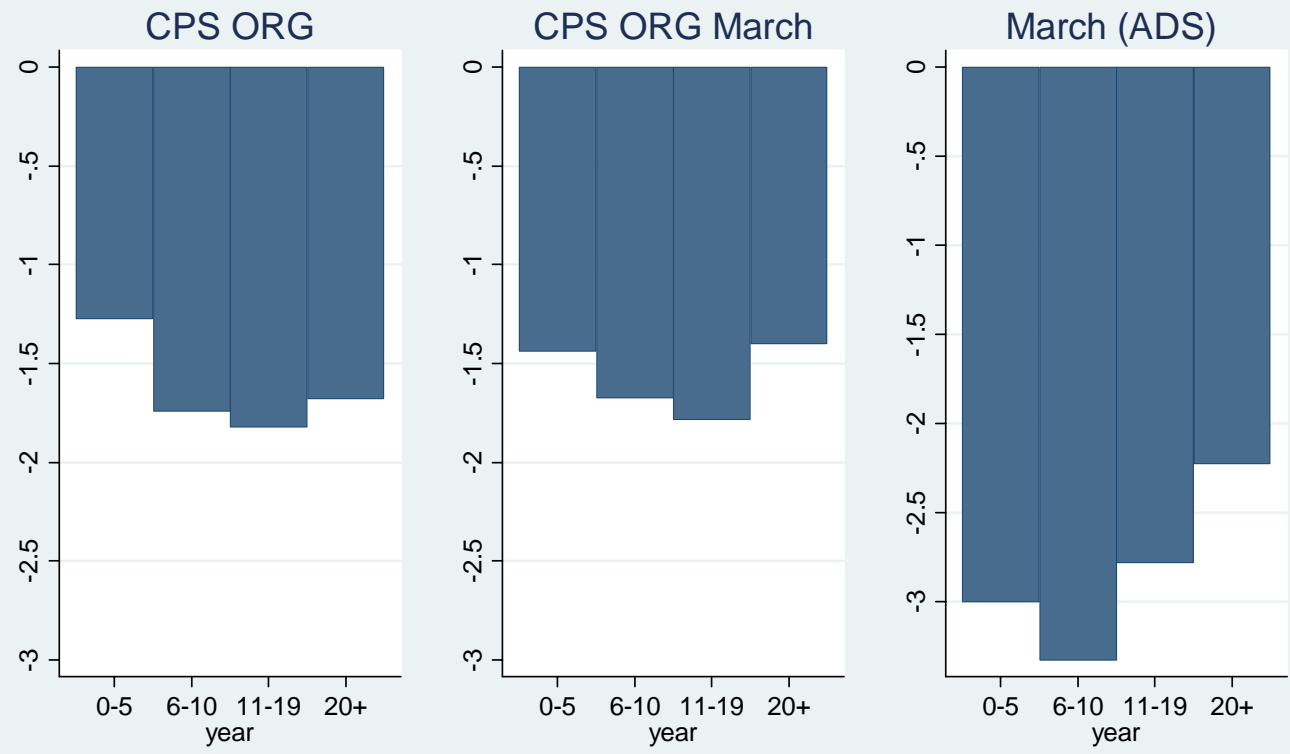

Sample: All employed males in the CPS ORG or March CPS 


\section{Figure 3:}

\section{Average Usual Hours of Work \& Years in the U.S.}
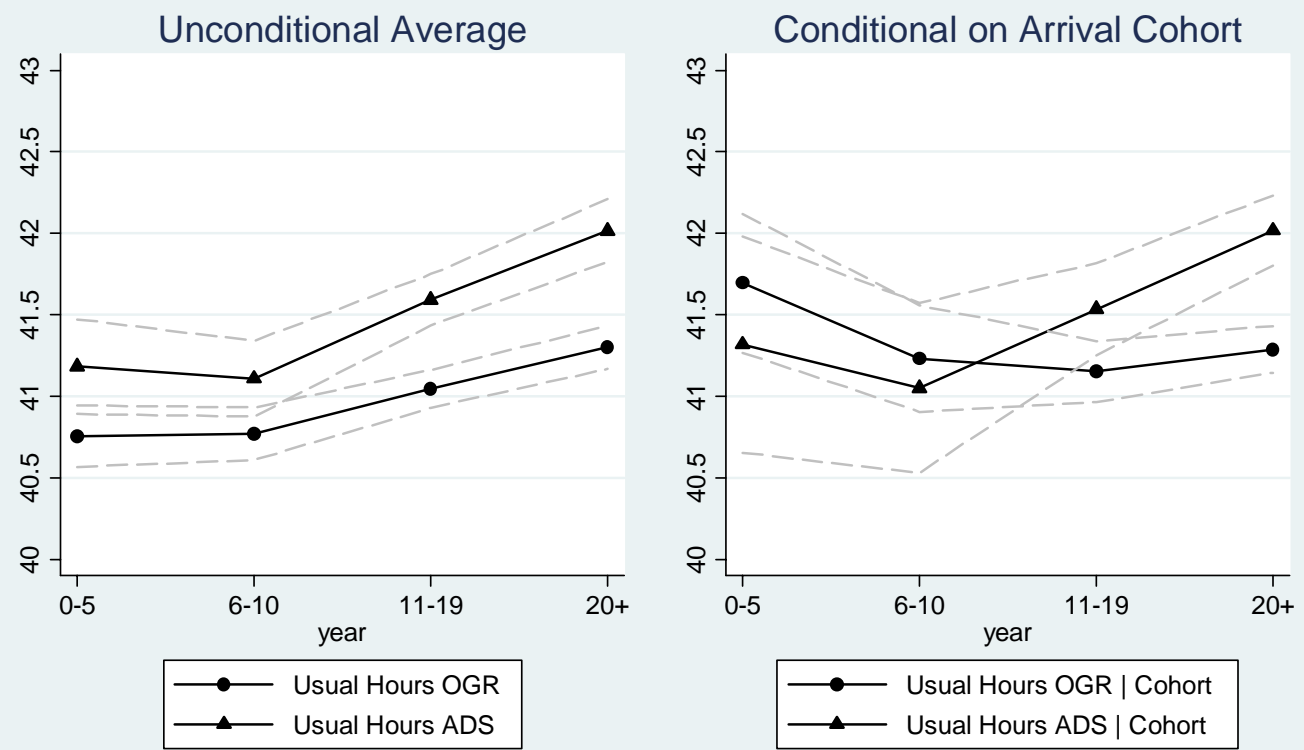

Sample: All employed males in the CPS ORG or March CPS Annual Demographic Files $95 \%$ Confidence Intervals presented in gray dash lines.

\section{Figure 4:}

\section{Proportion Immigrants from Mexico}

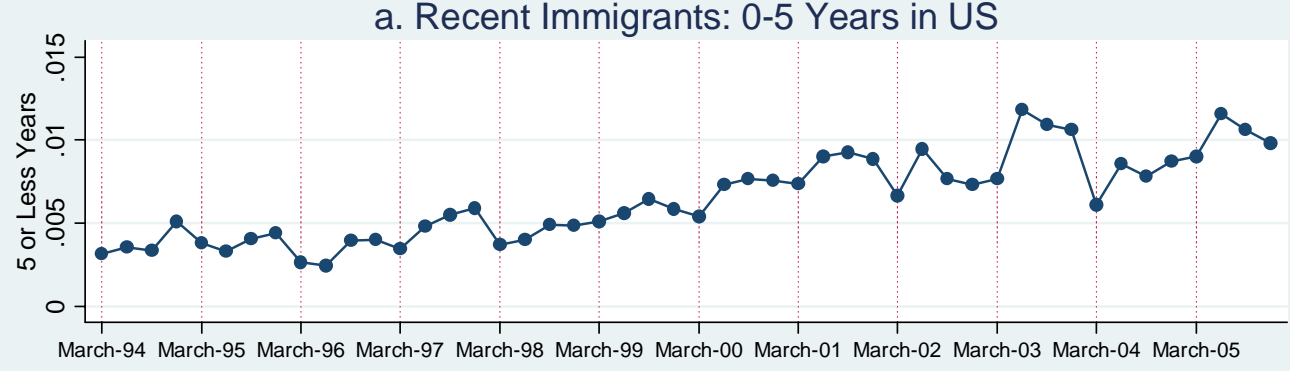

b. Earlier Immigrants: $6+$ Years in US

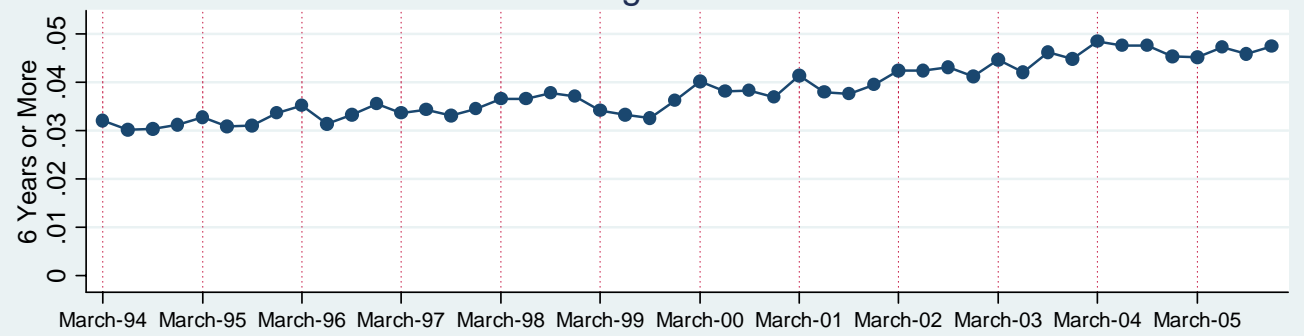

Source: All males in CPS ORG 1994-2006 
Figure 5:

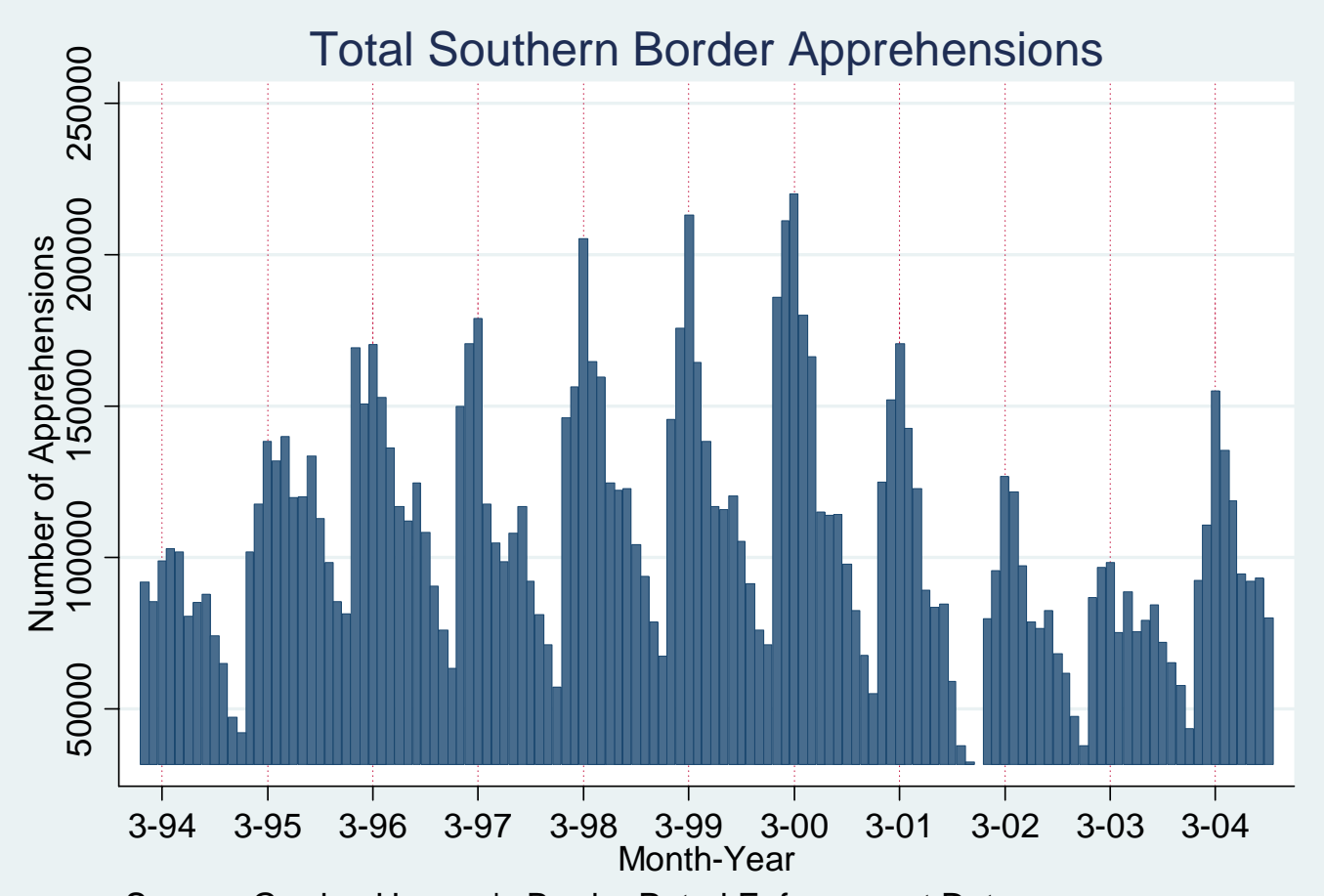

Source: Gordon Hanson's Border Patrol Enforcement Data 


\begin{tabular}{|c|c|c|c|c|c|c|c|c|c|c|c|c|c|c|}
\hline \multicolumn{3}{|c|}{$\begin{array}{c}\text { Table 1: Outgoing } \\
\text { Rotation GroupsEntry } \\
\text { of Rotation } \\
\text { by Month and Year } \\
\end{array}$} & \multicolumn{12}{|c|}{2007 Survey Month } \\
\hline Rotation & Year & Month & Jan & Feb & March & April & May & June & July & Aug & Sept & Oct & Nov & Dec \\
\hline 1 & 2005 & Oct & S8 & & & & & & & & & & & \\
\hline 2 & 2005 & Nov & S7 & S8 & & & & & & & & & & \\
\hline 3 & 2005 & Dec & S6 & S7 & S8 & & & & & & & & & \\
\hline 4 & 2006 & Jan & S5 & S6 & S7 & S8 & & & & & & & & \\
\hline 5 & 2006 & Feb & Off & S5 & S6 & S7 & S8 & & & & & & & \\
\hline 6 & 2006 & March & Off & Off & S5 & S6 & S7 & S8 & & & & & & \\
\hline 7 & 2006 & April & Off & Off & Off & S5 & S6 & S7 & S8 & & & & & \\
\hline 8 & 2006 & May & Off & Off & Off & Off & S5 & S6 & S7 & S8 & & & & \\
\hline 9 & 2006 & June & Off & Off & Off & Off & Off & S5 & S6 & S7 & S8 & & & \\
\hline 10 & 2006 & July & Off & Off & Off & Off & Off & Off & S5 & S6 & S7 & S8 & & \\
\hline 11 & 2006 & Aug & Off & Off & Off & Off & Off & Off & Off & S5 & S6 & S7 & S8 & \\
\hline 12 & 2006 & Sep & Off & Off & Off & Off & Off & Off & Off & Off & S5 & S6 & S7 & S8 \\
\hline 13 & 2006 & Oct & S4 & Off & Off & Off & Off & Off & Off & Off & Off & S5 & S6 & S7 \\
\hline 14 & 2006 & Nov & S3 & $\mathrm{S} 4$ & Off & Off & Off & Off & Off & Off & Off & Off & S5 & S6 \\
\hline 15 & 2006 & Dec & $\mathrm{S} 2$ & S3 & S4 & Off & Off & Off & Off & Off & Off & Off & Off & S5 \\
\hline 16 & 2007 & Jan & $\mathrm{S} 1$ & $\mathrm{~S} 2$ & S3 & S4 & Off & Off & Off & Off & Off & Off & Off & Off \\
\hline 17 & 2007 & Feb & & $\mathrm{S} 1$ & $\mathrm{~S} 2$ & S3 & $\mathrm{S4}$ & Off & Off & Off & Off & Off & Off & Off \\
\hline 18 & 2007 & March & & & $\mathrm{S} 1$ & $\mathrm{~S} 2$ & S3 & $\mathrm{S4}$ & Off & Off & Off & Off & Off & Off \\
\hline 19 & 2007 & April & & & & S1 & $\mathrm{S} 2$ & S3 & S4 & Off & Off & Off & Off & Off \\
\hline 20 & 2007 & May & & & & & $\mathrm{S} 1$ & $\mathrm{~S} 2$ & S3 & $\mathrm{S} 4$ & Off & Off & Off & Off \\
\hline 21 & 2007 & June & & & & & & $\mathrm{S} 1$ & $\mathrm{~S} 2$ & S3 & $\mathrm{S} 4$ & Off & Off & Off \\
\hline 22 & 2007 & July & & & & & & & $\mathrm{S} 1$ & $\mathrm{~S} 2$ & S3 & S4 & Off & Off \\
\hline 23 & 2007 & Aug & & & & & & & & S1 & S2 & S3 & S4 & Off \\
\hline 24 & 2007 & Sep & & & & & & & & & $\mathrm{S} 1$ & $\mathrm{~S} 2$ & S3 & $\mathrm{S} 4$ \\
\hline 25 & 2007 & Oct & & & & & & & & & & $\mathrm{S} 1$ & $\mathrm{~S} 2$ & S3 \\
\hline 26 & 2007 & Nov & & & & & & & & & & & S1 & S2 \\
\hline 27 & 2007 & Dec & & & & & & & & & & & & $\mathrm{S} 1$ \\
\hline
\end{tabular}


Table 2: Basic Demographic Characteristics

\begin{tabular}{|c|c|c|c|c|}
\hline & \multicolumn{2}{|c|}{ A) Using ORG } & \multicolumn{2}{|c|}{ B) Using March ADS } \\
\hline & $(1)$ & $(2)$ & $(3)$ & (4) \\
\hline & Natives & $\begin{array}{c}\text { Mexican } \\
\text { Immigrants }\end{array}$ & Natives & $\begin{array}{c}\text { Mexican } \\
\text { Immigrants }\end{array}$ \\
\hline \multicolumn{5}{|c|}{ All males in the sample } \\
\hline \multirow[t]{2}{*}{ Proportion } & 0.951 & 0.049 & 0.955 & 0.045 \\
\hline & $(0.000)$ & $(0.000)$ & $(0.000)$ & $(0.000)$ \\
\hline \multirow[t]{2}{*}{ Employed } & 0.801 & 0.862 & 0.818 & 0.859 \\
\hline & $(0.000)$ & $(0.002)$ & $(0.001)$ & $(0.002)$ \\
\hline \multirow[t]{2}{*}{ Age } & 42.758 & 37.619 & 42.945 & 37.795 \\
\hline & $(0.011)$ & $(0.050)$ & $(0.017)$ & $(0.060)$ \\
\hline \multirow[t]{2}{*}{ High School Dropouts } & 0.098 & 0.652 & 0.087 & 0.612 \\
\hline & $(0.000)$ & $(0.002)$ & $(0.000)$ & $(0.003)$ \\
\hline \multirow[t]{2}{*}{ High School Graduates } & 0.336 & 0.220 & 0.344 & 0.251 \\
\hline & $(0.001)$ & $(0.002)$ & $(0.001)$ & $(0.003)$ \\
\hline \multirow[t]{2}{*}{ Some College } & 0.274 & 0.084 & 0.271 & 0.088 \\
\hline & $(0.000)$ & $(0.001)$ & $(0.001)$ & $(0.002)$ \\
\hline \multirow[t]{3}{*}{ College Graduates } & 0.293 & 0.044 & 0.298 & 0.049 \\
\hline & $(0.000)$ & $(0.001)$ & $(0.001)$ & $(0.001)$ \\
\hline & 879,394 & 37,745 & 416,695 & 26,574 \\
\hline \multicolumn{5}{|c|}{ Only Employed Males } \\
\hline \multirow[t]{2}{*}{ Usual Hours Worked } & 42.985 & 41.021 & 44.316 & 41.572 \\
\hline & $(0.010)$ & $(0.036)$ & $(0.017)$ & $(0.052)$ \\
\hline \multirow[t]{2}{*}{ Weekly Earnings } & 699.895 & 372.571 & 751.709 & 382.295 \\
\hline & $(0.513)$ & $(1.231)$ & $(1.591)$ & $(2.762)$ \\
\hline Observations & 704,714 & 32,687 & 345,037 & 23,086 \\
\hline
\end{tabular}

Sample: All males in the CPS Outgoing Rotations and in the March Supplements age 25-64 (1994-2006). Standard errors in parenthesis. 
Table 3: Usual Average Hours of Work of Mexican Immigrant by Calendar Month

\begin{tabular}{|l|c|c|c|c|c|c|}
\hline & $(1)$ & $(2)$ & $(3)$ & $(4)$ & $(5)$ & $(6)$ \\
\hline & \multicolumn{3}{|c|}{ Raw Averages } & \multicolumn{2}{c|}{ Conditional on Arrival Cohort } \\
\hline & \multicolumn{2}{|c|}{$\begin{array}{c}\text { Recent } \\
\text { Immigrant }\end{array}$} & $\begin{array}{c}\text { Earlier } \\
\text { C-5 } \\
\text { Category }\end{array}$ & & & \multicolumn{2}{c|}{$\begin{array}{c}\text { Recent } \\
0-5\end{array}$} & $\begin{array}{c}\text { Earlier } \\
6+ \\
\text { Years }\end{array}$ & Difference & Years & Years & Difference \\
\hline January & 40.447 & 40.648 & 0.201 & 39.716 & 40.235 & 0.519 \\
\hline Feb & 40.202 & 40.991 & 0.789 & 39.71 & 40.597 & 0.887 \\
\hline March & 40.448 & 41.155 & 0.707 & 39.846 & 40.764 & 0.918 \\
\hline April & 40.406 & 41.108 & 0.702 & 39.819 & 40.702 & 0.883 \\
\hline May & 40.686 & 40.984 & 0.298 & 40.117 & 40.588 & 0.471 \\
\hline June & 41.27 & 41.269 & -0.001 & 40.768 & 40.878 & 0.11 \\
\hline July & 41.417 & 41.578 & 0.161 & 40.82 & 41.182 & 0.362 \\
\hline August & 41.253 & 41.282 & 0.029 & 40.658 & 40.889 & 0.231 \\
\hline September & 40.313 & 41.065 & 0.752 & 39.685 & 40.678 & 0.993 \\
\hline October & 41.253 & 41.177 & -0.076 & 40.586 & 40.771 & 0.185 \\
\hline November & 40.718 & 40.94 & 0.222 & 40.038 & 40.525 & 0.487 \\
\hline December & 40.298 & 40.601 & 0.303 & 39.673 & 40.196 & 0.523 \\
\hline
\end{tabular}

Sample: All males in the CPS Outgoing Rotations age 25-64.

Table 4. Years in the United States and Hours of Work

\begin{tabular}{|l|c|c|c|}
\hline & $(1)$ & $(2)$ & $(3)$ \\
\hline & CPS ORG & CPS Spring ORG & March ADS \\
\hline & 42.985 & 42.884 & 44.316 \\
\hline$(2)$ Natives 0 -5 Years & $(0.010)$ & $(0.020)$ & $(0.017)$ \\
\hline & 40.755 & 40.356 & 41.182 \\
\hline (3) 6-10 Years & $(0.096)$ & $(0.212)$ & $(0.148)$ \\
\hline & 40.771 & 40.649 & 41.108 \\
\hline (4) 11-20 Years & $(0.082)$ & $(0.169)$ & $(0.118)$ \\
\hline & 41.045 & 40.990 & 41.592 \\
\hline (5) 20 Years & $(0.059)$ & $(0.121)$ & $(0.080)$ \\
\hline & 41.301 & 41.477 & 42.017 \\
\hline Difference (5)-(2) & $(0.068)$ & $(0.134)$ & $(0.098)$ \\
\hline & $0.546 *$ & $1.121^{*}$ & $0.835^{*}$ \\
\hline Observations & $(0.117)$ & $(0.251)$ & $(0.177)$ \\
\hline
\end{tabular}

Sample: All employed immigrant males in the CPS Outgoing Rotations and March Supplements ages 25-64 (1994-2006) 
Table 5. Years in the United States and Hours of Work (Conditional on Arrival Cohort)

\begin{tabular}{|l|c|c|c|}
\hline & $(1)$ & $(2)$ & $(3)$ \\
\hline & CPS ORG & CPS Spring ORG & March ADS \\
\hline & 42.971 & 42.868 & 44.317 \\
\hline & $(0.012)$ & $(0.024)$ & $(0.022)$ \\
\hline & 41.694 & 41.431 & 41.318 \\
\hline (3) 0 -5 Years 6 -10 Years & $(0.217)$ & $(0.462)$ & $(0.338)$ \\
\hline & 41.231 & 41.192 & 41.051 \\
\hline (4) 11-20 Years & $(0.166)$ & $(0.352)$ & $(0.265)$ \\
\hline & 41.151 & 41.083 & 41.534 \\
\hline (5) 20 Years & $(0.095)$ & $(0.191)$ & $(0.144)$ \\
\hline & 41.288 & 41.464 & 42.018 \\
\hline Difference (5)-(2) & $(0.073)$ & $(0.145)$ & $(0.110)$ \\
\hline & -0.406 & 0.033 & $0.700 *$ \\
\hline Observations & $(0.232)$ & $(0.490)$ & $(0.360)$ \\
\hline
\end{tabular}

Sample: All employed males in the CPS Outgoing Rotations and March Supplements ages 25-64 (19942006)

Table 6: Characteristics of Mexican Immigrant Sample

\begin{tabular}{|l|c|c|c|}
\hline & $(1)$ & $(2)$ & $(3)$ \\
\hline & CPS ORG & $\begin{array}{c}\text { CPS ORG } \\
\text { March Only }\end{array}$ & March ADS \\
\hline Year Arrived & 1984.85 & 1984.35 & 1984.56 \\
\hline Age Arrived & $(0.054)$ & $(0.109)$ & $(0.065)$ \\
\hline & 21.622 & 21.209 & 21.495 \\
\hline US Experience & $(0.049)$ & $(0.099)$ & $(0.059)$ \\
\hline & 15.996 & 16.469 & 16.300 \\
\hline 0 -5 Years in US & $(0.051)$ & $(0.102)$ & $(0.062)$ \\
\hline & 0.150 & 0.125 & 0.143 \\
\hline 6-10 Years in US & $(0.002)$ & $(0.003)$ & $(0.002)$ \\
\hline & 0.186 & 0.191 & 0.182 \\
\hline 11-20 Years in US & $(0.002)$ & $(0.004)$ & $(0.002)$ \\
\hline & 0.357 & 0.360 & 0.357 \\
\hline 20+ Years in US & $(0.002)$ & $(0.005)$ & $(0.003)$ \\
\hline & 0.307 & 0.323 & 0.318 \\
\hline Observations & $(0.002)$ & $(0.005)$ & $(0.003)$ \\
\hline
\end{tabular}

Sample: All males in the CPS Outgoing Rotations and in the March Supplements age 25-64 (1994-2006). 
Table 7: Years in the United States for Employed and Unemployed Mexican Immigrants

\begin{tabular}{|l|c|c|c|c|}
\hline & \multicolumn{2}{|c|}{ CPS ORG } & \multicolumn{2}{c|}{ March ADS } \\
\hline & $(1)$ & $(2)$ & $(3)$ & Not Employed \\
\hline & Employed & Not Employed & Employed & 0.141 \\
\hline Proportion & 0.862 & 0.138 & 0.859 & $(0.002)$ \\
\hline Year Arrived & $(0.002)$ & $(0.002)$ & $(0.002)$ & 1982.366 \\
\hline & 1985.394 & 1981.462 & 1984.920 & $(0.200)$ \\
\hline US Experience & $(0.057)$ & $(0.168)$ & $(0.068)$ & 18.099 \\
\hline & 15.518 & 18.971 & 16.004 & $(0.192)$ \\
\hline 0-5 Years & $(0.053)$ & $(0.162)$ & $(0.064)$ & 0.142 \\
\hline & 0.885 & 0.115 & 0.858 & $(0.006)$ \\
\hline 6-10 Years & $(0.004)$ & $(0.004)$ & $(0.006)$ & 0.121 \\
\hline & 0.889 & 0.111 & 0.879 & $(0.005)$ \\
\hline 11-20 Years & $(0.004)$ & $(0.004)$ & $(0.005)$ & 0.119 \\
\hline & 0.886 & 0.114 & 0.881 & $(0.003)$ \\
\hline 20+ Years & $(0.003)$ & $(0.003)$ & $(0.003)$ & 0.178 \\
\hline & 0.806 & 0.194 & 0.822 & $(0.004)$ \\
\hline Observations & $(0.004)$ & $(0.004)$ & $(0.004)$ & 3,488 \\
\hline
\end{tabular}

Sample: All employed immigrant males in the CPS Outgoing Rotations and March Supplements ages 25-64 (1994-2006) 